\title{
Geological implications of continental magnetic anomalies derived from new CHAMP satellite data
}

\author{
Kumar Hemant* and Stefan Maus, GeoForschungsZentrum, Telegrafenberg, 14473, Potsdam
}

\section{Summary}

A GIS based modelling technique has been developed to model the various geological units of the continents starting from the UNESCO geological map of the world. Depending upon the known rock types of the region, they are assigned a standard susceptibility value and using the Crust2.1 seismic crustal structure, a vertically integrated susceptibility (VIS) model is computed at each point of the region. Starting with this initial VIS model, the total field anomaly is computed at a satellite altitude of $400 \mathrm{~km}$ and compared with the corresponding CHAMP total field anomaly map. The first comparison is carried out against a model using the lateral extent of a cratonic region as given by published tectonic maps. In the subsequent modelling step, depending upon the extent of the observed anomaly pattern of that region, the surface geology is extended beneath the sediments until the recomputed map fits the observed magnetic map. Here, we focus on modelling results for the mid-proterozoic province of the south-central USA, where a possible extension of an orogenic intrusion of granites and anorthosites under the Phanerozoic cover is investigated. The result gives a corrected boundary for this mid-proterozoic province. Similar modelling of CHAMP satellite magnetic anomalies can constrain the subsurface structure hidden by Phanerozoic cover in many parts of the world

\section{Introduction}

Magsat orbited at altitudes of $550 \mathrm{~km}$ down to $300 \mathrm{~km}$ from October 1979 to June 1980. Maps produced from Magsat data resolve magnetic features with wavelengths down to about $500 \mathrm{~km}$ (Langel et al., 1982; Ravat et al 1995; Sabaka et al 2000). However, inaccuracies of the star cameras affected the quality of the vector data. The launch of Oersted satellite in February 1999 after nearly a gap of two decades led to the derivation of highly accurate main field models (Olsen, 2002), but resolution of the crustal field was affected by the higher orbital altitude of the satellite $(600-800 \mathrm{~km})$. In July-2000, the CHAMP satellite (http://op.gfz-potsdam.de/champ/main_CHAMP.shtml) was launched into a low Earth orbit of $450 \mathrm{~km}$. The present altitude of its almost circular orbit is $400 \mathrm{~km}$. Its magnetometers resolve the crustal magnetic anomalies more accurately than any of its predecessors. Maus et al (2002), using the new CHAMP satellite scalar and vector data, derived a first global crustal anomaly map of the Total Intensity at $400 \mathrm{~km}$ altitude. Here, we use the first revision MF2 of this map (http://www.gfz-potsdam.de/pb2/pb23/ SatMag/model.html)
One objective of deriving these crustal field maps is to characterize the sources causing these anomalies and to interpret these maps in terms of known geology and try to infer new information on the regions hidden by Phanerozoic cover. The interpretation methods commonly employed often consist of visual comparison of an anomaly map with geologic or tectonic maps. Many of the earliest interpretive studies of satellite anomaly maps were of this type (Achache et al. 1987). More quantitative interpretations involve direct comparisons between geophysical quantities such as gravity, heat flow and the depth to the Moho. The ultimate aim, however, is to extract geological and tectonic information from the crustal anomaly maps and to explain the inferred magnetization in terms of tectonic and geologic processes. The distribution of magnetisation is not uniquely determined by the magnetic field and, hence, is often estimated using constraints from other geoscience data (e.g., surface geology, gravity, and heat flow). Whaler and Langel (1996) followed such methods to find the susceptibility and magnetization distributions.

Forward modelling methods based on global model of Hahn et al. (1984), derived from surface geology and seismic structure, assigned susceptibilities to 16 crustal types. Comparison of the modelled magnetic field showed some local agreement with measured anomaly maps, but in general, their models did not reproduce the observed anomaly features. Using inverse methods, Purucker et al. (1998) derived an equivalent source magnetization model (SEMM) by modifying an initial a priori model SEMM-0 until the resulting anomaly pattern matched a Magsatderived magnetic anomaly map in a least-squares sense. SEMM models were presented in terms of the product of susceptibility times thickness.

The work presented here is based on a GIS modelling technique developed to model the various geological units of the continents and oceans using a standard geological map. Depending upon the known rock types of the region, they are assigned a standard susceptibility value and, using the global seismic crustal structure, a vertically integrated susceptibility (VIS) model is computed at each point of the region. Starting with this initial VIS model, the total field anomaly is computed at an altitude of $400 \mathrm{~km}$ and compared with the corresponding region of the CHAMP total field anomaly map. The model derived here serves as an a-priori model. In the next iteration the lower crustal parameters are changed to improve the fit between the predicted and observed magnetic anomaly map. The final map is then used to draw inferences regarding the tectonic 


\section{Geological implications of continental magnetic anomalies}

and geologic features underlying the younger crust and the nature of the less-understood lower crust. One of the important assumptions in our work is to consider the seismic Moho as a magnetic boundary (Wasilewski and Mayhew, 1992).

\section{Modelling}

The sources of the continental magnetic anomalies primarily consist of rock types formed early in the geological history of the earth. A glance at the observed magnetic anomaly map and the geological map of the world clearly points to the fact that most of the anomalies lie over the geological regions Precambrian in age. However, the exposed Precambrian rocks constitute only $29 \%$ of the total Precambrian crust (Goodwin, 1991). This means that a significant portion of the oldest crust on Earth is overlain by Phanerozoic cover. Hence, our aim is to look for the possible extensions of the Precambrian units obscured by younger cover and possibly add to the existing information of geological boundaries of the Precambrian units. For this, it is necessary first to consider the known geology of the region and its boundary at the surface. Subsequently, using our modeling procedure, the total field anomaly map is computed for the region and compared with the corresponding region of CHAMP magnetic anomaly map. The next step involves modifying the boundary of the region and re-computing the anomaly map until a reasonable fit is achieved with the observed anomaly map.

Our primary interest is to generate an a-priori model based on the information of the rock types exposed, their magnetic susceptibility value and the known stratigraphy for that region. The input data required for modelling is discussed subsequently. The first of our input is the world geological map (CGWM UNESCO, 2000), which shows the distribution of geology based on their ages. However, it does not provide any detail about the rock types known in a particular geological region. This gap is filled in with the information of rock types from the compilation of various tectonic maps. Combining the geological and tectonic maps helps us to formulate a first order a-priori model. The global seismic model of Mooney et al (1998), Crust2.1 (latest model), is incorporated to use the estimated thickness of crust for a region. The last of the input is the standard volume susceptibility chart taken from standard sources (Clark and Emerson, 1991; Hunt, C. P et al. , 1995). Each of these inputs are combined to formulate an a-priori model which is discussed in the following subsections.

Consider all the known rock types for a particular geological region and perform a mathematical average using their maximum volume susceptibility value from the standard charts (Clark and Emerson, 1991; Hunt, C. P et al. , 1995). The actual susceptibility of all the rock types is some percentage of this maximum value, which is considered to be a constant for all the geological provinces of the world. The next step is to generate the vertically integrated susceptibility (VIS) model. This requires the thickness information for each geological stratum within a vertical column and is generally known from the stratigraphy of that region as shown in Fig (1). The thickness is multiplied with the bulk susceptibility of that stratum. Integrating the susceptibility times thickness information for various layers in a vertical column (Fig 1), provides the VIS value for that region.

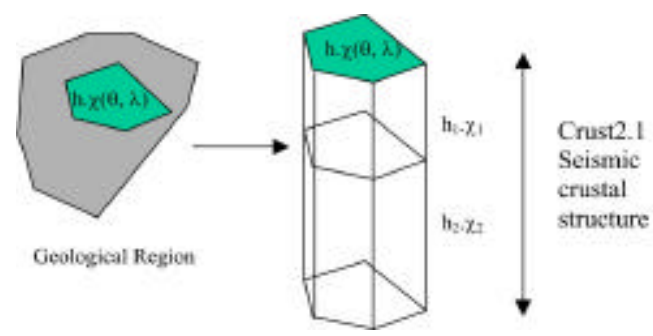

Figure 1: Diagram shows a geological cross-section of a region, for which a VIS value is computed.

Each such geological province is modelled following the above steps and each such VIS value is knit together to generate the global VIS model, which serves as an a-priori model. Modeling is done on the GIS ArcInfo 8.1 platform.

To compute the total field anomaly of the VIS model, the magnetic potential is computed and spherical harmonic degrees 1-15 are set to zero because this long wavelength crustal field is masked by the main field and is not observable. The total field anomaly is then computed against a main field model (Olsen 2002), which is also used as an inducing field. Finally, only spherical harmonic degrees 16-80 of the model field are compared with the corresponding degrees $16-80$ of the observed crustal field.

\section{Results}

Central Province (Belt) is a large structural province, which underlies the south-central USA, encircling the southern portion of the North American platform. The rocks of this province are exposed only in a few places in Colorado and California. Large anorogenic magmatic activity is dominant along the entire stretch of this province (Goodwin, 1991). We present the modeling results for the largely buried midproterozoic province at south-central USA following the work by Anderson (1983). Figure (2) shows the tectonic boundary for this province as envisaged by Anderson (1983) following the anorogenic granite intrusion in the upper crust. The granites and associated anorthosites in this province are of two ages flanking the eastern and the 


\section{Geological implications of continental magnetic anomalies}

western halves. Major subprovinces of 1.34-1.4 Ga and 1.42-1.5 Ga granites occur in these two halves (Fig 2). These anorogenic granites are A-type granites enriched in $\mathrm{K}$ and $\mathrm{Fe}$ and depleted in $\mathrm{Ca}, \mathrm{Mg}$ and $\mathrm{Sr}$ relative to $\mathrm{I}-$ and S-type granitic bodies.

The present extent of the boundary of this buried midproterozoic province is fed as input to the GIS based model as shown in Figure 3. The upper crustal thickness derived from seismic model crust2.1 is multiplied with the susceptibility of the granites and anorthosites. The lower crustal thickness is multiplied with the same susceptibility as above, but multiplied by a factor 1.3 , consistent with definition of Taylor and McLennan, (1985). The surrounding Phanerozoic cover is assumed to be a typical continental rock and a constant susceptibility value is assigned. The susceptibility distribution is shown in Figure 4. Using the above methodology, the total field anomaly map is computed at an altitude of $400 \mathrm{~km}$ for spherical harmonic degrees 16-80. The observed and computed anomaly map is shown in Figure 5 and 6 respectively.

The observed total field anomaly map for the spherical harmonic degrees 16-80 is shown in Figure 5. The map shows one of the largest stretches of anomalies on Earth in the Southwest USA. The sources of the anomaly are attributed to the mid-proterozoic province, dominated by the anorogenic granitic intrusion in the crust.

The computed anomaly map (Fig. 6), shows an apparent mismatch in the extent of the anomaly as compared to the observed map in Figure 5. The extension of the anomaly in the southwestern region of the province is missing in the observed map. Further in the eastern half, the high anomaly extends up to the base of Lake Michigan. This differs significantly from the observed map, which shows an ovalshaped anomaly high only in the Kentucky-Tennessee region. Obviously, the extension of the mid-proterozoic region needs to be redefined especially in the regions where the intrusion has affected the entire column of the crust.

Figure 7 shows the computed total field anomaly map for the redefined boundary (marked in red in Fig. 3) of the granitic intrusion where it is most intense and occupies almost the entire crust. The observed and the computed map now agree very well. The oval at the KentuckyTennessee region is reproduced accurately. The anomaly pattern in the southwest of the province agrees extremely well. The extension of this anomaly in the northeast direction following up to the base of the Lake Michigan, however, is not reproduced quite as well. This could, however, be explained by a shallower seismic crustal thickness in this region.

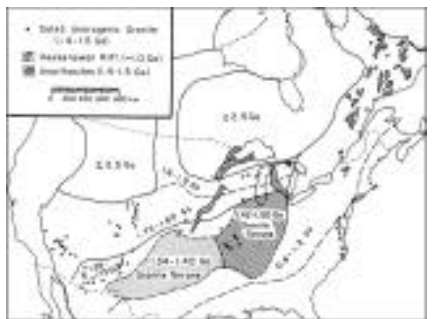

Figure 2: Distribution of major Mid-proterozoic anorogenic granites and anorthosites in North America. (Anderson, 1983).

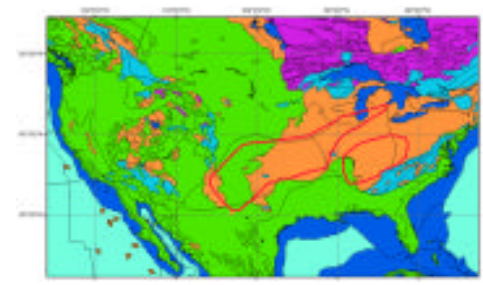

Figure 3: The geological map of the southwest USA region. Thin black line is the previous boundary and the red line marks the new boundary.
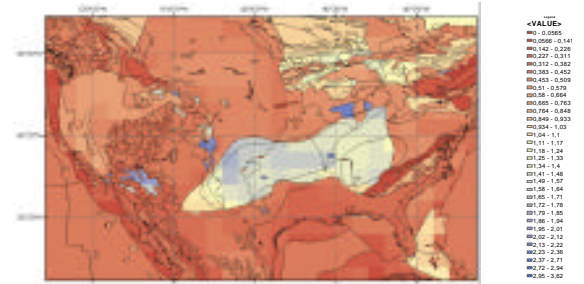

Figure 4: The vertically Integrated susceptibility (VIS) map of the southwest USA region.

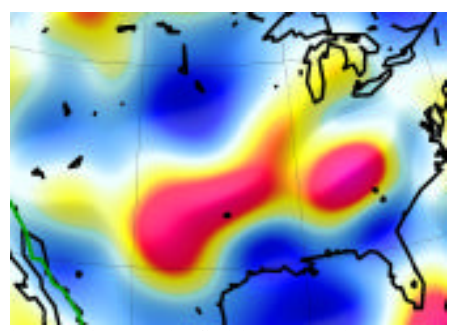

Figure 5: Observed Total field anomaly map for spherical harmonic degrees (16-80) at an altitude of $400 \mathrm{~km}$ for the southwest USA region.

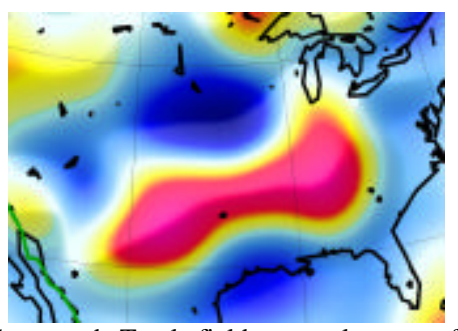

Figure 6: Computed Total field anomaly map for spherical harmonic degrees (16-80) at an altitude of $400 \mathrm{~km}$ following the boundary of mid-proterozoic province shown in Fig.2. 


\section{Geological implications of continental magnetic anomalies}

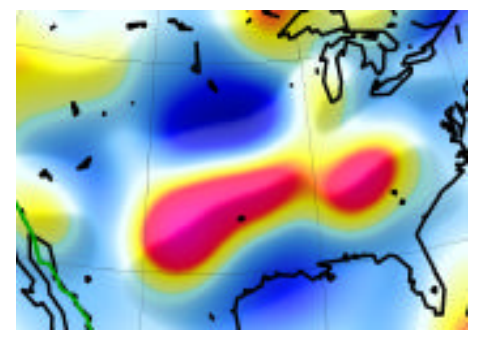

Figure 7: Computed Total field anomaly map for spherical harmonic degrees (16-80) at an altitude of $400 \mathrm{~km}$ using the redefined boundary marked in red (Fig 3).

\section{Conclusion}

Magnetic modelling of a mid-proterozoic granitic province using a GIS based technique demonstrates the advantages of this technique of inferring geological and tectonic information from the new satellite magnetic maps. The boundaries of the largely buried mid-proterozoic province can be traced effectively from the satellite observations. This would not have been possible by the conventional magnetic methods. These modelling capabilities can help us explore and provide new insights to the less-understood regions of the world. Over the coming years, a continuous stream of high quality magnetic data from several near Earth satellites will yield increasingly accurate crustal field models. The new field models will thus provide a new basis for the study of crustal composition, their lateral and possibly also their vertical extension. These results can provide important constraints for future geological and geophysical models and help to redefine the boundaries of the tectonic units.

\section{References}

Achache, J., Abtout, A., and LeMouel, J.L., 1987, The downward continuation of Magsat crustal anomaly field over Southeast Asia, J. Geophys. Res., 92, 11584-96.

Anderson, J.L., 1983, Proterozoic anorogenic plutonism of North America. Geol. Soc. America Mem., 161, 133-154.

Clark, D.A., and Emerson, D.W., 1991, Notes on rock magnetization characteristics in applied geophysical studies, Exploration Geophysics, 22, 547-55.

Geological Map of the World, 2000, Commission for the Geological Map of the World (CGMW) / (C) UNESCO Publishing.

Goodwin, A.M., 1991, Precambrian Geology, Academic Press, London.
Hahn, A., Ahrendt, H., Jeyer, J., and hufen, J. -H., 1984, A model of magnetic sources within the earth's crust compatible with the field measured by the satellite Magsat, Geol. Jb., A75, 125-56.

Hunt, C. P., Moskowitz, B.M. and Banerjee, S.K., 1995, Magnetic properties of Rocks and Minerals, In : Rock Physics and Phase Relations -A handbook of Physical constants, AGU Reference shelf 3, etd. Ahrens, T.J.

Langel, R.A., Estes, R.H., and Mead, G. D., 1982, Some new methods in geomagnetic field modelling applied to the 1960-1980 epoch, J. Geomag. Geoelectr., 34, 327-349.

Maus, S., Rother, M., Holme, R., Luhr, H., Olsen, N., Haak, V., 2002, First CHAMP satellite magnetic data resolve uncertainty about strength of the lithospheric magnetic field, Geophys. Res. Letts. 29, (14)

Mooney, W.D., Laske, G., and Masters, T.G., 1998, CRUST 5.1: A global crustal model at $5^{0}$ X $5^{0}$, J. Geophys. Res., 103, 727-747.

Olsen, N., 2002, A model of the Geomagnetic Main Field and its Secular Variation for Epoch 2000. (Geophys. J. Int. in press)

Purucker, M.E., Langel, R.A, Rajaram, M., and Raymond, C., 1998, Global magnetization models with a priori information, J. Geophys. Res., 103, 2563-2584.

Ravat, D., Langel, R.A., Purucker, M., Arkani-Hamed, J., and Alsdorf, D.E., 1995, Global vector and scalar Magsat magnetic anomaly maps, J. Geophys. Res., 100, B10, 20111-20136.

Sabaka, T. J., Olsen, n., and Langel, R. A., 2000, A comprehensive model of the near-Earth Magnetic Field: Phase 3. NASA/TM-2000-209894, National Aeronautics and Sapce Administration, Goddard Space Flight Center, Greenbelt, Maryland.

Taylor, S.R., and McLennan, S.M., 1985, The Continental Crust: Its composition and Evolution. Oxford: Blackwell Scientific Publ. 312pp.

Wasilewski, P.J., and Mayhew, M.A., 1992, The Moho as a magnetic boundary revisited, Geophys. Res. Lett., 19, 2259-62.

Whaler, K.A., and Langel, R.A., 1996, Minimal crustal magnetizations from satellite data, Phys. Earth Planet Int., 48, 303-319. 